\title{
Influence of Technological Parameters of Production on Properties of Tinplate TH 550, CA
}

\author{
Emil Spišák ${ }^{1, *}$, Marek Čižmár ${ }^{2}$, Janka Majerníková ${ }^{1}$ \\ ${ }^{1 *}$ Technical University of Košice, Faculty of Mechanical Engineering, Department of Engineering Technologies and Materials, Košice, Slovakia, \\ 2 US Steel, Ltd. Košice, Slovakia.
}

\begin{abstract}
The paper was focused on analysis of mechanical properties determined by the uniaxial tensile test and their comparison with production parameters (coiling temperature, finishing temperature, 1st stand reduction and 2nd stand reduction) pertaining to $\mathrm{TH}$ 550, CA material. The thicknesses of tinplates were 0.15 $-0.18 \mathrm{~mm}$.
\end{abstract}

Keywords: tinplate; uniaxial tensile test; finishing temperature; coiling temperature.

\section{Introduction}

Steel sheet is still one of progressive materials. It is suitable for production of shape-demanding low-weight rigid parts. Amongst other end uses, steel sheet is also used to produce broad range of steel packaging: barrels, drums, canisters, cans, boxes, lids and caps. These parts are usually produced by drawing.

In recent years, light-gauge steel sheet used in packaging industry is one of the major thin steel sheet products made in U.S.Steel, s.r.o. Košice. Its annual production increased from 40,000 to 400,000 tons per year. Currently the thickness of the tinplated sheets is reduced significantly (from the original $0.24 \mathrm{~mm}$ to the current $0.14 \div 0.18 \mathrm{~mm}$ ). This is achieved using so-called second reduction aimed at achieving the required thickness. The second reduction significantly modifies mechanical and technological properties of such produced sheets. As majority of tin grades are processed by drawing, marginal formability characteristics of these steel sheets need to be determined as well.

Due to this reason it is necessary to have sufficient knowledge of strength and plastic properties, as well as tolerance intervals that are criterion for assessing quality of coils. Producers and processors of packaging sheets currently use various testing methods and testing devices. One of the methods is the uniaxial tensile test. This is why this paper focuses on analysis of mechanical properties determined by the uniaxial tensile test and their comparison with production parameters (coiling temperature, finishing temperature, 1st stand reduction in \% and 2nd stand reduction in \%) pertaining to DR 550, CA material.

\section{Experimental material}

Tinplates are currently produces mainly two ways of rolling. Thicker steel sheets $(0.18-0.30 \mathrm{~mm})$ are produced by single reduction, after which the plates ate continuous annealed. The sheets of smaller thickness $(0.13-0.18 \mathrm{~mm})$ are after the single reduction and annealing a second time rolled (double reduced - DR). The resulting product has higher hardness and strength after double reduction 
compared to a single reduced material. The finalization of packaging sheet production is the process of double side electrolytic tinning. The tin layer fulfills anticorrosive function of this sheet.

DR tinplated sheet, currently very frequently used, was used during experiments. Customers demand light gauge and high strength tinplated sheets. Double-reduced steel sheet of grade $\mathrm{TH}$ 550, CA, was used; the samples' thickness was 0.15 $\mathrm{mm}$ to $0.18 \mathrm{~mm}$. 60 samples were evaluated. Prior to their second reduction, the sheets had been continuously annealed (CA). The yield strength and the elongation were determined by the uniaxial tensile test. Production parameters of Hot Strip Mill (HSM) were added to the measured mechanical properties (coiling temperature, finishing temperature), as well as production parameters from Two Stand Mill (1st stand reduction in \%, 2nd stand reduction in \%). Table 1 contains mechanical properties of tin sheets in accordance with SEFL.

Table 1: Mechanical properties of tested material in accordance with SEFL.

\begin{tabular}{|c|c|c|c|c|}
$\begin{array}{c}\text { Tested } \\
\text { material }\end{array}$ & $\begin{array}{c}\mathbf{R}_{\mathbf{p} 0,2} \\
\text { [MPa] }\end{array}$ & $\begin{array}{c}\mathbf{R}_{\mathbf{m}} \\
\text { [MPa] }\end{array}$ & $\begin{array}{c}\text { HR30Tm } \\
\text { [\%] }\end{array}$ & $\begin{array}{c}\text { Thickness } \\
\text { [mm] }\end{array}$ \\
\hline TH 550, CA & $500-600$ & $520-620$ & $70-76$ & $0.13-0.40$ \\
\hline
\end{tabular}

\section{The uniaxial tensile test}

This is the most commonly used test, following rules stated in STN EN 10002-1+AC1 and STN 42 0321 that determine the testing method and shape of tested sample.

The objective of the uniaxial tensile test is to obtain the values of basic mechanical properties: $R_{e}\left(R_{p 0.2}\right)$ - yield strength, $R_{m}$ - tensile strength, $A_{50}$ - elongation, $A_{H}$ - uniform elongation, $r$ - normal anisotropy coefficient, $\mathrm{n}$ - exponent of strength hardening.

\section{Results and Discussion}

Continuously annealed material with thickness of $0.15-0.18 \mathrm{~mm}$ was subjected to testing. The results of yield strength, tensile strength and elongation of tested materials are shown on Fig. 1, 2 and 3. In the Fig. 4, 5 and 6 are shown comparisons of mechanical properties for material TH 550, CA. In the Fig. 7, 8 and 9 are shown comparisons of mechanical properties based on coiling temperature and finishing temperature at HSM, as well as the 1st stand and 2nd stand reduction at Two Stand Mill.

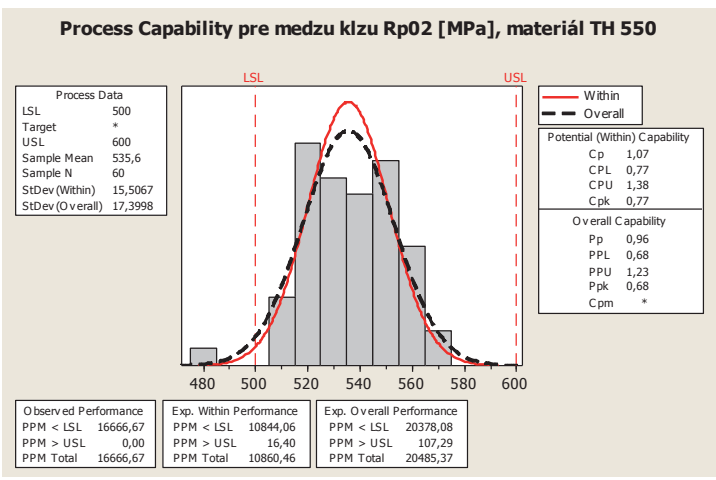

Fig. 1: Process capability for yield strength Rpo.2 of material TH 550, CA.

The values of the yield strength $\mathrm{R}_{\mathrm{p} 0.2}$ of material TH 550, CA is between 484 and $573 \mathrm{MPa}$. The lower measured values are outside of the scope determined by EN standard. From Fig. 1 it can concluded, that the most of the measured values Rpo. 2 are in range between $520-560 \mathrm{MPa}$. The average value of $R_{p 0.2}$ is $535 \mathrm{MPa}$.

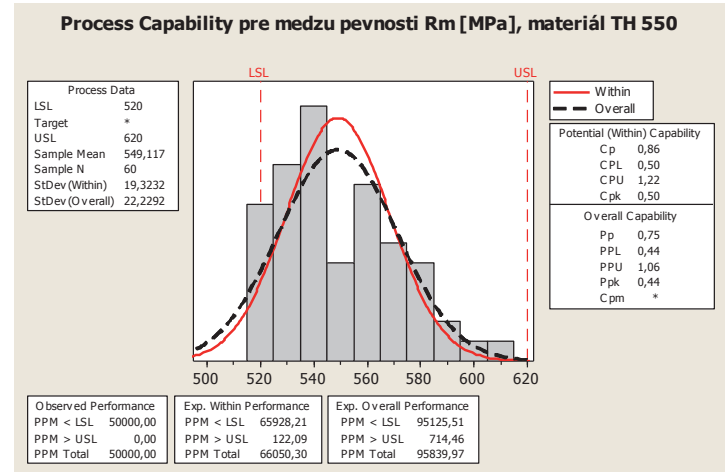

Fig. 2: Process capability for tensile strength $R_{m}$ of material TH550, $C A$.

The values of the tensile strength $\mathrm{Rm}_{\mathrm{m}}$ of material $\mathrm{TH}$ 550, CA is between 516 and $615 \mathrm{MPa}$. The lower measured values are below the minimum value of tensile strength (520 MPa). From Fig. 2 it can concluded, that the greatest frequency of the measured values $R_{m}$ is at $540 \mathrm{MPa}$. The higher frequency of the measured tensile strength is the $550 \mathrm{MPa}$.

In the Fig. 3 is shows histogram of the measured elongations $\mathrm{A}_{50}$ of material TH 550, CA. Elongation has not defined upper and lower limit as yield 


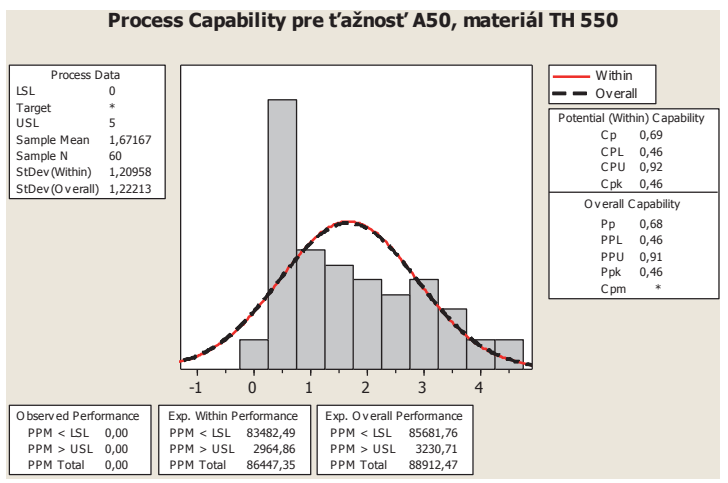

Fig. 3: Process capability for elongation A50 of material TH 550, CA.

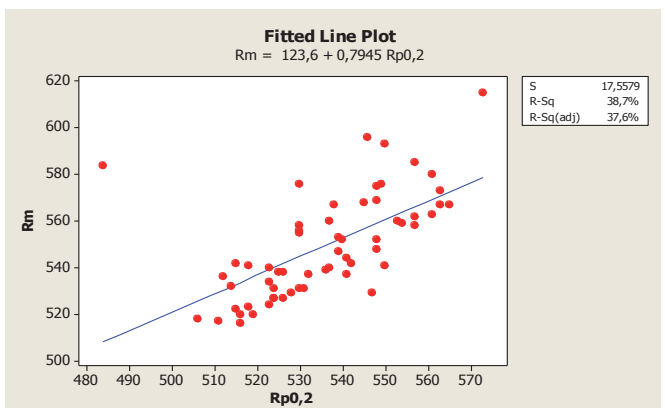

Fig. 4: Comparison of yield strength Rpo.2 with tensile strength $R_{m}$ for material TH 550, CA.

strength Rp0.2 or tensile strength $\mathrm{Rm}_{\mathrm{m}}$ for these materials. The measured values of elongation of tested samples ranged from 0.2 to $4.7 \%$.

The dependence of tensile strength and yield strength shown in Fig. 4 shows a growth trend. In general it can say that with the increasing of yield strength grow tensile strength of tested materials.

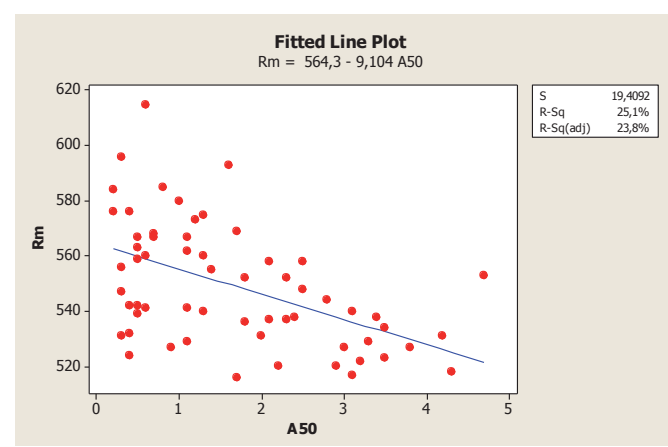

Fig. 5: Comparison of elongation Aso with tensile strength $R_{m}$ for material TH 550, CA.

In Fig. 5 has been measured decreasing trend of tensile strength with increasing elongation $A_{50}$. Scattering of measured values is very large and therefore mathematical dependence can be considered unusable. The same applies depending on the yield strength and elongation A50 (Fig. 6).

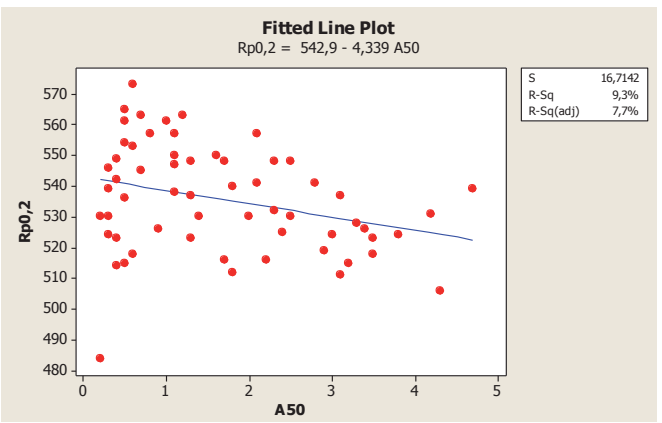

Fig. 6: Comparison of elongation Aso and yield strength Rp0.2 for material TH 550, CA.

From the comparisons in Fig. 7 - 9, which show dependence of yield strength $R_{p 0.2^{\prime}}$ tensile strength $R_{m}$ and elongation $A_{50}$ to finishing temperature, coiling temperature at HSM as well as the 1 st stand and 2 nd stand reduction at Two Stand Mill can be concluded that it is impossible to establish a clear dependence between evaluated parameters. Scattering of measured results is too large and calculated correlation coefficients for the dependences (table 2) are very low and on this basis we can not talk of the growing trend, respectively decreasing trend.

Table 2: Calculated correlation coefficients for material TH 550, CA.

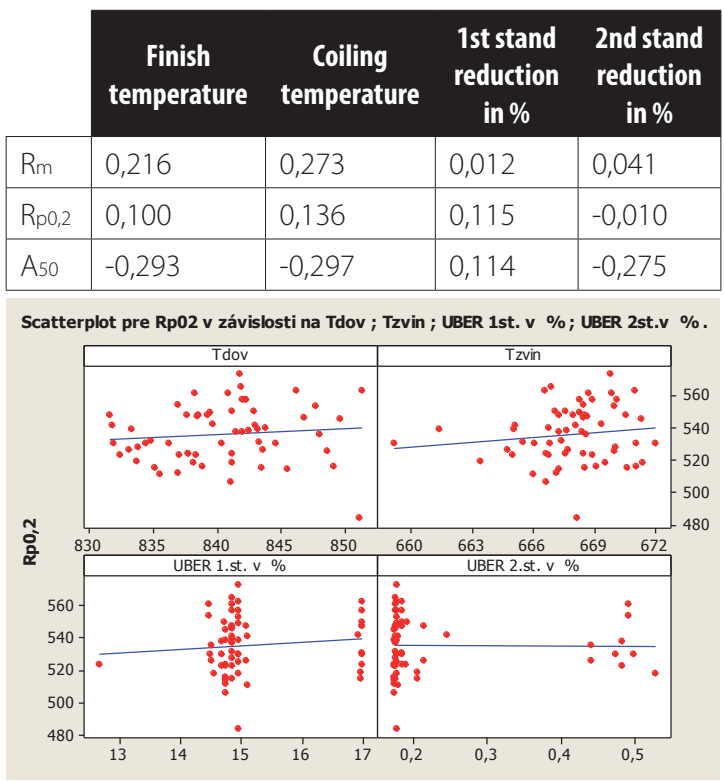

Fig. 7: Comparison of yield strength and finishing temperature, coiling temperature and eductions of 1 st and 2nd stand for material TH 550,CA. 


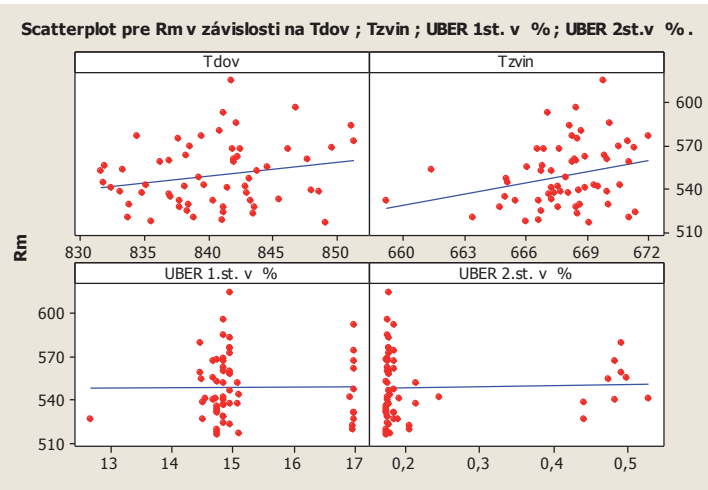

Fig. 8: Comparison of tensile strength and finishing temperature, coiling temperature and reductions at 1st and 2nd stand for material TH 550,CA.

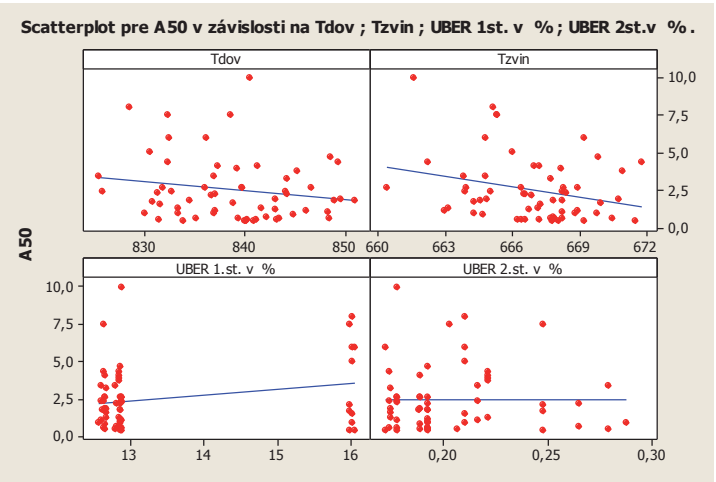

Fig. 9: Comparison of elongation and finishing temperature, coiling temperature and reductions at 1st and 2nd stand for material TH 550,CA

\section{Conclusions}

In the paper were evaluated mechanical and plastic properties of the material TH 550, thicknesses 0.15 to $0.18 \mathrm{~mm}$, continuous annealing. Mechanical and plastic properties were evaluated by uniaxial tensile test. For the experiment were selected 60 samples of tested material. The tested material has been produced at a different finishing temperature, coiling temperature and a different reduction of material on the 1 st and the 2 nd rolling stand. From the measured results it can be concluded that the tested sheets has not been found a clear correlation between yield strength $R_{p 0.2}$, tensile strength $R_{m}$ and elongation $A_{50}$ and conditions for producing these sheets, which represented finishing temperature, coiling temperature, material reduction on the 1 st stand and 2 nd stand. The measured results of elongation $A_{50}$ by uniaxial tensile test showed a very large scattering and the mean value is very low. From these results, we can state that uniaxial tensile test doesn't reflect objectively the plastic properties of tested material.

\section{Acknowledgments \\ The authors are grateful to APVV for support of experimental work under grant APVV-14-0834 and the project VEGA No. $1 / 0872 / 14$}

\section{References}

[1] Pittner, J., Simaan, M.A. (2010). Tandem Cold Metal Rolling Mill Control. Using Practical Advanced Methods. New York, p. 205.

[2] Sharma, R.C. (2003). Principles of Heat Treatment of Steel. New Age International, pp. 87-99.

[3] Banabic, D., Bunge, H.J., Pöhlandt, K., Tekkaya, A. E. (2000). Formability of Metallic Materials. Springer - Verlag Berlin Heidelberg. ISBN: 3-540-67906-5.

[4] Ma, J., Yu, G., Jiang, S., Yang, C. (2012). Research progress on tinplate annealing process. Jinshu Rechuli/Heat Treatment of Metals, Vol. 37 (5), p. 77-80.

[5] Marciniak, Z., Dunca, J.L., Hu, S.J. (2002). Mechanics of Sheet Metal Forming. London. Edward Arnold. p. 231.

[6] Murphy, T.P. (2011). Tin and Tinplate. Uhlig's Corrosion Handbook: Third Edition. p. 853-860.

[7] Wang, X., Zhu, Z., Cai, F., Li, H. (2013). Effects of continuous annealing process on microstructure and properties of electrolytic tinplate. Heat Treatment of Metals. Vol. 38 (6). p. 49-54.

[8] Pittner, J., Simaan, M. A. (2010). Tandem Cold Metal Rolling Mill Control. Using Practical Advanced Methods. New York. p. 205.

[9] Spišák, E., Slota, J., Majerníková, J., Kaščák, L’., Malega, P. (2012). Inhomogeneous plastic deformation of tinplates under uniaxial stress state. Chemické listy. Vol. 106, no. Symposia, p. 537-540

[10] Spišák, E., Slota, J., Majerníková, J. (2010). The evaluation of mechanical properties of tinplates as input parameters for simulation of deep drawing processes. Metalurgija. Vol. 49, no. 2. p. 528-532.

[11] Spišák, E., Majerníková, J. (2013). Analysis of variance of mechanical properties of sheets as the input parameters for simulation ofprocesses. Acta Metallurgica Slovaca. Vol. 18, no. 2-3. p. 109-116

[12] Spišák, E., Majerníková, J., Spišáková E. (2015). The causes of corrosion formation of packaging sheets after plastic deformation. Materials Science Forum. Vol. 818. p. 121-124.

[13] Spišák, E., Majerníková, J. (2013). Continual annealed single rolled sheets and evaluation of their properties. Journal of 
manufacturing and industrial engineering. Vol. 12, no. 3-4. p. 30-34.

[14] Zhang, J., Jiang, Y. (2004). A Study of Inhomogeneous Plastic Deformation of 1045 Steel, Journal Engineering Materials Technoly. Vol. 126. p. 164-172.

\section{Biographical notes}

Emil Spišák, prof. Ing., CSc., (born 1955) is a professor of the Department of Technologies and Materials, Faculty of Mechanical Engineering, Technical University of Košice. He is head of the Department of Engineering Technologies and Materials and director of the Institute of Technologies and Management. He served as Vice-Dean for 4 years and Vice-Rector for 11 years. He works in the area of evaluating of material properties, material failures, analysis and quantification of production factors influence in production of thin steel sheet stamping parts, modelling and simulation of technological processes, mainly forming processes. He is national secretary and member of International Deep-Drawing Research Group. He is an author of 6 monographs and more than 490 publications in journals and conference proceedings at Slovakia and abroad. His published works were cited 200 times. He has been worked on 60 grant projects, research tasks and 67 projects solved for industry.

Marek Čižmár, Ing. (born 1974) is an external Ph.D. student. He works in US Steel, Ltd. Košice.

Janka Majerníková, doc. Ing., PhD. (born 1966) is an associate professor at the Department of Technologies and Materials, Faculty of Mechanical Engineering, Technical University of Košice. She received scientific degree Ph.D. in 2008 in the field of limit strains of tinplates by different stress-strain states. She is an author of 3 monographs and more than 100 publications in journals and conference proceedings in Slovakia and abroad. Her published works were cited 27 times. She has been worked on several grant projects. 